Received: December 11, 2017

\title{
Research on the Design Method of Physical Education Curriculum Based on the Flipped Classroom Concept
}

\author{
Ying Bai ${ }^{1}$ \\ Department of Physical Education, Northeastern University
}

\begin{abstract}
The emergence of the flipped classroom concept provides a good way to improve teaching. This paper takes the flipped classroom theory as the starting point and applies this concept to physical education for the design of physical education curriculum. The effect is analyzed, which proves good implementation and effectiveness and is of reference significance for the improvement of teaching in China and the promotion of the flipped classroom concept.
\end{abstract}

\section{Keywords}

Flipped Classroom Concept $\bullet$ Physical Education $\bullet$ Teaching $\bullet$ Curriculum Design

\footnotetext{
${ }^{1}$ Correspondence to: Ying Bai (MA), Department of physical education, Northeastern University, Shenyang 110819, China. Email: 9535078@qq.com

Citation: Bai, Y. (2018). Research on the Design Method of Physical Education Curriculum Based on the Flipped
Classroom Concept. Educational $\quad$ Sciences: Theory \& Practice,
http://dx.doi.org/10.12738/estp.2018.5.059


With the development of our society, people have attached more and more importance to the reform of education and the cultivation of talents. The traditional teaching is mainly based on knowledge imparting with relatively simple form, which tends to ignore the state and receiving ability of learners (Mcparland \& Noble, 2010). Nowadays, information technology is developing rapidly and the information technology has been widely applied in education, which has revolutionized the method, content and form of teaching and promotes the innovative development of teaching (Sung, 2006; Maddux, Cummings \& Torresrivera, 1999). How to integrate information technology with teaching reasonably to maximize the effect of teaching is the key to teaching improvement.

Physical education, as a popular item, is not actually loved by many people. The traditional teaching mode of physical education has long been unable to adapt to the development of modern teaching. However, there lacks experience and method in the application of information technology in physical education curriculum, so it cannot be well integrated (Cai \& Zhang, 2017). The concept of "flipped classroom" is a big step forward in educational reform (Wei \& Qiu, 2014). It can apply information technology flexibly in teaching, fully consider the daily behaviors of students and promote the learning enthusiasm of students, which is conducive to the potential development of students (Herreid \& Schiller, 2013; Gilboy, Heinerichs \& Pazzaglia, 2015; Hyunwoo K, 2018).

This paper takes the flipped classroom theory as the starting point and applies this concept to physical education for the design of physical education curriculum. The effect is analyzed, which is of reference significance for the improvement of teaching in China and the promotion of the flipped classroom concept.

\section{Concept and Characteristics of Flipped Classroom}

The concept of flipped classroom has attracted much attention since its introduction in China in 2011. On the macro level, the so-called flipped classroom, is the application of information technology to achieve an organic combination of network teaching and on-site teaching through the Internet (Roehl, Reddy \& Shannon, 2013); at the micro level, it can be understood as that students use extracurricular time to learn through instructional videos and the classroom teaching is for the interaction, communication and Q\&A between students and teachers (Dawson, 2015).

It can be seen from the concept of flipped classroom that this concept has the following characteristics: informationization, individualization, diversification and comprehensiveness of teaching, networked teaching platform, optimization of resources and consciousness of students (Pierce \& Fox, 2012). Compared with traditional teaching, the focus has shifted from teaching to learning and students are taken as the main body. Diversified teaching resources and forms are applied and the full communication before, during and after class has activated the learning atmosphere and broadened the knowledge scope. The learning enthusiasm of students is enhanced through peer review, which promotes the autonomous learning of enable them to learn more efficiently. 


\section{Design of Physical Education Curriculum}

\section{Target design}

The flipped classroom advocates learning first and teaching behind. Before class, students are required to study independently and ensure the effect of learning, the premise of which is that students must have higher consciousness. The most important thing in consciousness is to stimulate students' interest and correct their attitude and motivation of learning, which requires a positive, active, competitive and friendly learning environment.

Each student has their own level and personality and they can be grouped according to individual differences. The learning objectives are formulated according to the situation of each group. The students in the same group can communicate with each other, supervise each other and achieve mutual improvement. Pre-class learning is mainly through the network and physical education teachers should select appropriate content for each group based on a variety of different teaching content they have made beforehand. Each group can choose the courses they are interested in under the premise of completing the teaching objectives. On the network learning platform, students can also upload their own achievements in physical education, such as basketball dunks, football shots and other wonderful photos or videos to the network learning platform. Teachers and students can browse and comment on the platform to form a vibrant atmosphere, thus enhancing the learning enthusiasm of students.

The objectives in physical education mainly include four aspects: the first is to instruct the physical knowledge and skill learned by students before the class, answer their questions, discover their mistakes and standardize their action and method; the second is to carry out sports practice to achieve the effect of exercise; the third is to carry out various sports activities starting with students' emotions to enhance the learning enthusiasm, promote mutual friendship and learn the ways of doing things from sports; the fourth is to improve the comprehensive ability and promote the comprehensive development of students through the combination of theory and practice.

The objectives after physical education mainly include four aspects: the first is that students should review and summarize to gain new insights through reviewing old materials; the second is that teachers should reflect on the curriculum and improve the curriculum design to enhance the teaching effect.

\section{Curriculum design}

The curriculum design is divided into pre-class, in-class and post-class design.

The key to pre-class design lies in the construction of the network teaching platform. The quality of the platform largely determines the effect pre-class learning. The teaching platform should bear two characteristics. The first is functional maturation. It needs to be equipped with various functions required for teaching, which should facilitate the teaching of teachers and learning of students. The second is friendly interface, which can catch students' eyes and attract their attention, thus enhancing the learning enthusiasm and efficiency. The 
function of the platform should include the following aspects: the first is the uploading of resources, network viewing and downloading. Moreover, various formats of resources can be realized, such as video, document data; the second is the platform of communication. Interactive communication and question discussion between teachers and students, students and students can be achieved on this platform; the third is the platform of achievement exhibition. Students can show their learning results on this platform, which can be displayed in groups or individually; the fourth is the platform of evaluation. Students can participate in exams and teacher can review and analyze their performance on this platform; the fifth is about other teaching assistance functions, such as notification, teaching information, and sending and receiving of assignment.

Table 1

The Curriculum Design of Regular Physical Education

\begin{tabular}{|c|c|c|c|}
\hline Category & $\begin{array}{c}\text { Time } \\
\text { (Minutes) }\end{array}$ & Teaching Arrangements & Basic Modes \\
\hline \multirow[b]{2}{*}{$\begin{array}{l}\text { Preparation } \\
\text { part }\end{array}$} & \multirow[b]{2}{*}{20} & 1.Conventional content & $\begin{array}{l}\text { Dress the ranks, check on work } \\
\text { attendance and so on }\end{array}$ \\
\hline & & 2.Warm-up & $\begin{array}{l}\text { 1. Regular practice } \\
\text { 2. General practice } \\
\text { 3. Specialized practice }\end{array}$ \\
\hline \multirow{6}{*}{ Essential part } & 10 & 1. Question and Answer & Explain and demonstrate \\
\hline & 10 & $\begin{array}{l}\text { 2.Standardize actions of the } \mathrm{P} \text {. } \\
\text { E. skill motion }\end{array}$ & Teacher leads students to exercise \\
\hline & 20 & 3. Sport skill training & $\begin{array}{l}\text { Work in groups and practice the sport } \\
\text { skill }\end{array}$ \\
\hline & 10 & 4.Discuss the question of P.E. & Group discussion \\
\hline & 20 & 5.Achievement exhibition & $\begin{array}{l}\text { 1. Group show } \\
\text { 2. Comment on each other } \\
\text { 3. Teacher comments }\end{array}$ \\
\hline & 15 & 6.Physical quality training & Sports competition and so on \\
\hline \multirow[b]{2}{*}{$\begin{array}{l}\text { Concluding } \\
\text { part }\end{array}$} & \multirow[b]{2}{*}{5} & 1. Cooling down & Teacher leads students to exercise \\
\hline & & 2. Class Summary & $\begin{array}{l}\text { 1.The pe teacher give a summary } \\
\text { 2.Assign a student to make a } \\
\text { summary }\end{array}$ \\
\hline
\end{tabular}

The in-class design is different from the traditional teaching style. In the flipped classroom mode, the inclass teaching is mainly practice-oriented. The theoretical explanation has been done through the network and the in-class teaching is mainly the practice of theory. For regular physical education curriculum, it can be designed according to the following table. When certain learning effect is achieved, the curriculum can focus on sports activities, such as track and field competitions, fun basketball games and fun sports games.

In the curriculum design, the purpose of physical exercise, improvement of the quality of all aspects, enhancement of the learning enthusiasm, teamwork spirit and strengthening of friendship can be achieved through the guidance of students' sports action, technical training, answering and discussion of problems and the development of physical practice activities.

The key to post-class design is to improve the self-evaluation summary ability of students. For physical education curriculum, most students will not reflect on and consolidate the content of physical education. The survey data of several classes in a school is shown in the following Figure and it can be seen that only less than $5 \%$ of students will consolidate the content they learn after class. In response to this situation, teachers can use 
the network teaching platform to ask students to submit post-class summary reports and it will be directly associated with the course score. At the same time, fun games based on the content of the curriculum can be designed to achieve the consolidation effect.

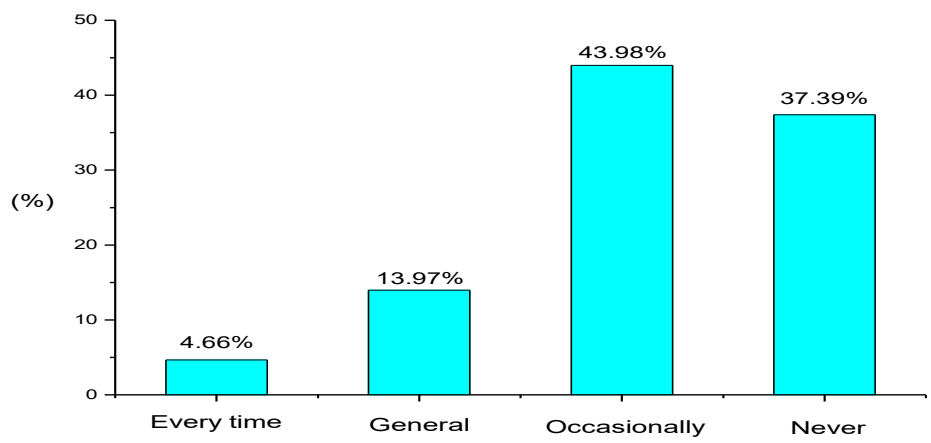

Figure 1. The circumstances of students reinforcement learning.

\section{Teaching evaluation}

The evaluation of the learning effect of student' is not only based on the final exam, but needs to run through before, during and after the class. The design is as follows: course discussion accounts for $20 \%$ of the total score; network exam accounts for $20 \%$; assignment accounts for $30 \%$; learning performance accounts for $10 \%$; and final exam accounts for $20 \%$. The course discussion can use the number of posting and replying on the problem discussion on the network teaching platform as the scoring basis. The network exam is set up after each network course, which can give students multiple opportunities, with the highest score as the final score. The purpose is to help students master theoretical knowledge independently; the form of assignment scoring is the combination of peer review of students and the scoring of teachers so that students can learn from each other and the fairness can be ensured; the learning performance is scored from the participation and enthusiasm of students. Students who actively participate in each class can be given full marks; there is only one opportunity for final exam and it is based on the score of students.

In addition to evaluating the learning of students, students can also evaluate teachers and the network learning platforms so that improvement can be made based on the opinions of students, thus optimizing the teaching effectiveness.

\section{Practice of Physical Education Curriculum}

The physical education curriculum is designed according to the above content. The practice object is a certain class of a university. Three theoretical courses and 13 practical courses are designed, each lasting 2 hours. The SaKai teaching platform is taken as the network teaching platform. During and after the physical education curriculum, participants are asked to participate in the questionnaire survey and satisfaction evaluation and statistical analysis will be conducted. 
The statistics on the participation of students in the physical education curriculum are shown in Figure 2. The statistics of the students' post-class reflection and consolidation of the content are shown in Figure 3.
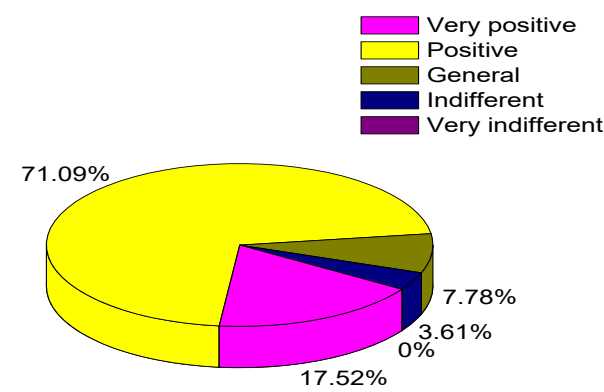

Figure 2. The circumstances of students discussing the question of P.E.

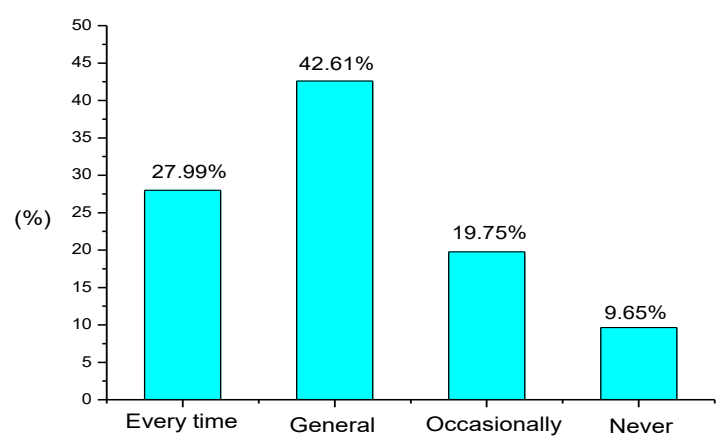

Figure 3. The circumstances of student's reinforcement learning for new physical education curriculum.

It can be seen from Figure 2 that students are highly motivated to participate in the discussion. Comparing Figure 1 and Figure 3, the students' post-class reflection on the content is significantly improved through this curriculum design.
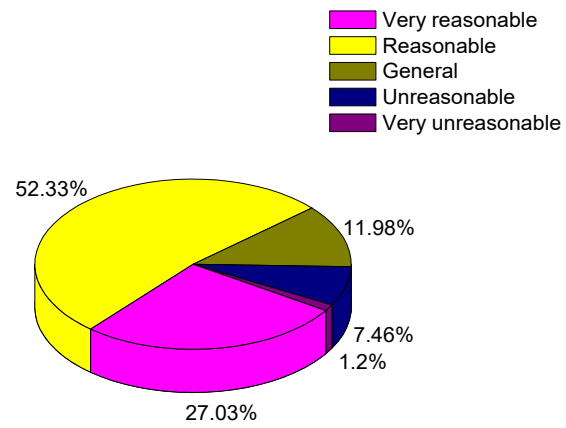

Figure 4. The degree of satisfaction for the evaluation method. 
The statistics on the satisfaction of students with the performance evaluation method of the physical education curriculum is shown in Figure 4. It can be seen that most students have a good evaluation of the, indicating the rationality of the evaluation method.

The exercise effect of students in the physical education curriculum is shown in Figure 5 and their recognition of the physical education curriculum is shown in Figure 6.

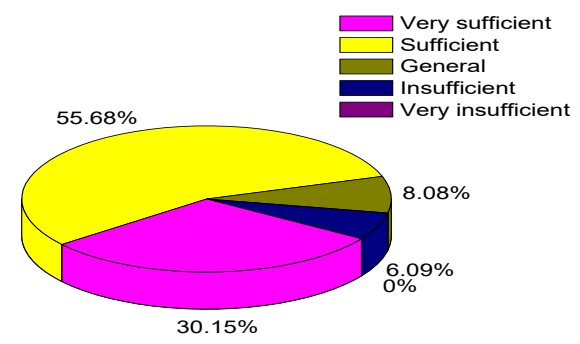

Figure 5. The effect of the new P.E.

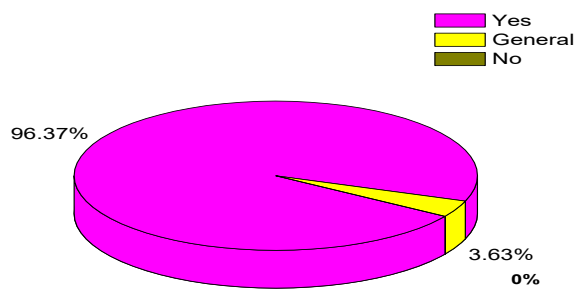

Figure 6. The recognition of the new P.E.

It can be seen from Figure 5 that the physical and mental health of most of students has been exercised. Only few individuals think that the exercise is not enough. This is related to the enthusiasm of participation and teachers can adjust accordingly based on their interests. It can be seen from Figure 6 that the physical education curriculum is welcomed and recognized by students, indicating the implementation and effectiveness of the physical education curriculum based on the flipped classroom concept.

\section{Conclusion}

Based on the flipped classroom concept, this paper studies the design of physical education curriculum and conducts the practice comparison. The following conclusions are drawn:

(1) Based on the flipped classroom concept, the teaching curriculum design for the physical education curriculum is proposed;

(2) The curriculum practice shows that the curriculum design can improve the enthusiasm, exercise effect and quality of various aspects of students, which is of good implementation and effectiveness. 


\section{References}

Cai, J. Y., \& Zhang, P. P. (2017). The support environment construction for teaching and research of physical education based on emerging information technology. Journal of Computational \& Theoretical Nanoscience, 14(4), 2015-2020. http://dx.doi.org/10.1166/jctn.2017.6536

Dawson, P. (2015). Motivation and cognitive load in the flipped classroom: definition, rationale and a call for research. Higher Education Research \& Development, 34(1), 1-14. http://dx.doi.org/10.1080/07294360.2014.934336

Gilboy, M. B., Heinerichs, S., \& Pazzaglia, G. (2015). Enhancing student engagement using the flipped classroom. Journal of Nutrition Education \& Behavior, 47(1), 109-114. http://dx.doi.org/10.1016/j.jneb.2014.08.008

Herreid, C. F., \& Schiller, N. A. (2013). Case study: Case studies and the flipped classroom. Journal of College Science Teaching, 42(5), 62-67.

Hyunwoo K., Seyong J. (2018), Effects of competition anxiety on self-confidence in soccer players: Modulation effects of home and away games, Journal of Men's Health, 14(3), e62-e68; DOI: 10.22374/18756859.14.3.9

Maddux, C. D., Cummings, R., \& Torresrivera, E. (1999). Facilitating the integration of information technology into higher-education instruction. Educational Technology, 39, 430-9.

Mcparland, M., \& Noble, L. G. (2010). The effectiveness of problem-based learning compared to traditional teaching in undergraduate psychiatry. Medical Education, 38(8), 859-867. http://dx.doi.org/10.1111/j.13652929.2004.01818.x

Pierce R, \& Fox J. (2012). Vodcasts and active-learning exercises in a "flipped classroom" model of a renal pharmacotherapy module. American Journal of Pharmaceutical Education, 76(10), 196. http://dx.doi.org/10.5688/ajpe7610196

Roehl, A., Reddy, S. L., \& Shannon, G. J. (2013). The flipped classroom: An opportunity to engage millennial students through active learning strategies. Journal of Family \& Consumer Sciences, 105, 44. http://dx.doi.org/10.14307/JFCS105.2.12

Sung, Y. T. (2006). Web-based tools for designing and developing teaching materials for integration of information technology into instruction. Journal of Educational Technology \& Society, 9(4), 139-149.

Wei, D. D., \& Qiu, L. X. (2014). Research on application of "flipped class" model in teacher education. Applied Mechanics \& Materials, 644-650, 5756-5760. http://dx.doi.org/10.4028/www.scientific.net/AMM.644650.5756 